\title{
ESTIMATES OF VARIANCE COMPONENTS AND HERITABILITIES OF PRE- WEANING GROWTH TRAITS OF BARKI AND RAHMANI LAMBS
}

\author{
M.H. Hammoud and M.M.I. Salem \\ Department of Animal Production, Faculty of Agriculture, Alexandria University, PC: 21545, Alexandria, \\ Egypt
}

\section{SUMMARY}

Data representing 594 Barki and 582 Rahmani lambs raised at Alexandria University Experimental Station between 1991-2011 were utilized in this study to estimate variance components and heritability of birth weight $(B W)$, weaning weight $(W W)$ and average daily gain $(A D G)$ from birth to weaning of lambs. Also, the effects of season and year of lambing, sex of lamb, type of lambing and parity on the previous traits were studied.

The analysis indicated that fixed effects on all studied traits were generally significant $(P<0.01$ or $P<0.05)$ except for effects of season and year of lambing on BW of Barki lambs and effects of parity on ADG of both breeds. Variance components and heritability for the studied traits were estimated using the Wombat programme fitting four univariate animal models. Estimates of the direct heritability $\left(h^{2}{ }_{a}\right)$ and maternal heritability $\left(h^{2}\right)$ were ranged from 0.161-0.353 and 0.145-0.147, from 0.100-0.171 and 0.124-0.124 and from 0.014-0.172 and 0.119-0.121 for BW, WW and ADG of Barki lambs, respectively, the corresponding values for Rahmani lambs ranged from 0.204-0.519 and 0.094-0.215, from 0.139-0.168 and 0-0.021 and from 0.125-0.144 and0-0.001, respectively. Ignoring maternal effects from the model resulted in an over estimation of direct heritability of all traits of both breeds. Estimates of the total heritability $\left(h^{2}\right)$ were moderate to high for BW and low for $W W$ and $A D G$ of both breeds. Estimates of the total maternal effect $\left(t_{m}\right)$ were considerable for all studied traits of both breeds. The results in general showed that maternal effects were significant source of variation for early growth traits of Barki and Rahmani lambs. Therefore, these effects should be considered when carrying out genetic evaluations of early growth traits of Barki and Rahmani lambs in this flock.

Keywords: Variance components, heritability, maternal effect, pre-weaning growth, Barki, Rahmani, lambs

\section{INTRODUCTION}

The total number of sheep population in Egypt was 5450000 heads in 2013, and they contribute about $6 \%$ of the national total red meat (FAOSTAT, 2015). Barki and Rahmani sheep are considered as two of the three major sheep breeds in the country.

Early growth traits of lamb are important factors influencing profitability in any sheep producing enterprise (Mokhatri et al., 2012, Javed et al., 2013, Mohammadi et al., 2013 and Jannoune et al., 2015). Growth traits of lambs are determined not only by lamb's genetic potential for growth but also by maternal genetic and permanent and temporary environmental effects (Mandal et al., 2006, Behzadi et al., 2007, Rashidiet al., 2008, Baneh et al., 2010, Bayeriya et al., 2011, and Javed et al., 2013). Studies of various sheep breeds have shown that both direct and maternal genetic influences are of importance for lamb growth (Rashidi et al., 2008,Baneh et al., 2010, Gowane et al., 2010, Mokhatri et al., 2012, Javed et al., 2013 and Akthar et al., 2014). Knowledge of variance components and heritability is necessary for the determination of an optimal breeding strategy seeking the genetic improvement of the lambs' growth traits (Baneh et al., 2010, Tosh and Kemp, 2011, Jafari et al., 2012, Javed et al., 2013, Mohammadi et al., 2013, Roshanfek et al., 2015 and Lalit et al., 2016).
This investigation was carried out to estimate variance components and heritabilities of birth weight, weaning weight and pre-weaning average daily gain of Barki and Rahmani lambs in Egypt.

\section{MATERIALS AND METHODS}

Data:

Data for this study were from the records of the sheep flock of the Experimental Station, Faculty of Agriculture, Alexandria University. The records covered the period from 1991 to 2011 and were relevant to 594 and 582 Barki and Rahmani lambs presenting17 and 16 rams, 181 and 190 ewes, respectively.

Animals were housed in semi closed pens, fed on berseem (Trifolium alexandrinum) during winter and spring and on stubble and berseem hay and/ or fodder sorghum (Sorghum bicolor) during summer and autumn. Supplementary concentrate ration of about $0.25 \mathrm{~kg} /$ head were offered daily along the year. The structures of data are presented in Table (1).

The flock was managed for all year round lambing. Females were first mated at about 18 months of age. Rams and ewes were selected as yearlings on the basis of visual appraisal for type and size rather than on a pre-set intensive selection program. Once the ewe entered the breeding flock, there is no chance for culling until the end of its productive life. 
Table 1. Means, standard deviations (SD), coefficient of variation (CV\%) and distributions of the data for birth weight (BW), weaning weights (WW) and average daily gain (ADG) of Barki and Rahmani lambs

\begin{tabular}{lcccccc}
\hline \multirow{2}{*}{ Items } & \multicolumn{3}{c}{ Barki } & \multicolumn{3}{c}{ Rahmani } \\
\cline { 2 - 7 } & BW & WW & ADG, gm. & BW & WW & ADG,gm. \\
\hline Mean , (kg) & 3.70 & 20.90 & 143.09 & 3.52 & 20.71 & 142.62 \\
SD, (kg) & 0.60 & 4.64 & 37.00 & 0.59 & 4.27 & 33.82 \\
C.V (\%) & 16.25 & 22.18 & 25.86 & 16.74 & 20.63 & 23.71 \\
No. of records & 594 & 532 & 532 & 582 & 500 & 500 \\
No. of sires & 17 & 17 & 17 & 16 & 16 & 16 \\
No. of dams & 181 & 172 & 172 & 190 & 174 & 174 \\
No. of ram lambs & 312 & 282 & 282 & 289 & 246 & 246 \\
No. of ewe lambs & 282 & 250 & 250 & 293 & 254 & 254 \\
No, single lambs & 534 & 476 & 476 & 390 & 336 & 336 \\
No, twin lambs & 60 & 56 & 56 & 192 & 164 & 164 \\
\hline
\end{tabular}

\section{Statistical procedures:}

Least squares of GLM procedure (SAS 2008) were utilize to test the significance of the fixed effects of season of lambing (4 seasons), year of lambing (7 periods), sex (male and female), type of lambing (single and twin) and parity (8 parities) on birth weight $(\mathrm{BW})$, weaning weight $(\mathrm{WW})$ and average daily gain (ADG) from birth to weaning of lambs. Lambing was classified by season into autumn lambing between September and November, winter lambing between December and February, spring lambing between March and May and summer lambing between June and August.Each breed data were analyzed separately. The statistical model fitted was:

$\mathrm{Y}_{\mathrm{ijkl} m n}=\mu+\mathrm{A}_{\mathrm{i}}+{ }_{\mathrm{Bj}}+\mathrm{C}_{\mathrm{k}}+\mathrm{D}_{1}+\mathrm{P}_{\mathrm{m}}+\mathrm{e}_{\mathrm{ijk} k \mathrm{mn}}$ where,

$\mathrm{Y}_{\mathrm{ijklmn}}$ : either $\mathrm{BW}, \mathrm{WW}$ or $\mathrm{ADG} ; \mu$ : an underlying constant specific to each trait; $A_{i}$ : the fixed effect of $i^{\text {th }}$ season of lambing; $B_{j}$ : the fixed effect of $j^{\text {th }}$ year of lambing; $C_{k}$ : the fixed effect of $k^{\text {th }}$ sex; $D_{1}$ : the fixed effect of $1^{\text {th }}$ type of lambing; $P_{m}$ : the fixed effect of $\mathrm{m}^{\text {th }}$ parity and $\mathrm{e}_{\mathrm{ijklmn}}$ : random residual assumed to be independent normally distributed with mean zero and variance $\sigma_{e}^{2}$.

Univariate animal models were fitted to estimate (co)variance components for each trait using Wombat program (Meyer, 2006). The following four models were used:

$$
\begin{aligned}
& y=X b+Z_{a} a+e \\
& y=X b+Z_{a} a+Z_{c} c+e \\
& y=X b+Z_{a} a+Z_{m} m+e \\
& y=X b+Z_{a} a+Z_{m} m+Z_{c} c+e
\end{aligned}
$$

where $\mathrm{y}$ is a $\mathrm{n} \times 1$ vector of observations for each trait; b, a, m, c and e are vectors of fixed effects (birth year, season of birth, parity of dam, sex and birth status of lambs), direct additive genetic effects, maternal additive genetic effects, permanent environmental effects of dam and the residual effects, respectively; $X, Z_{\mathrm{a}}, Z_{\mathrm{m}}, Z_{\mathrm{c}}$ are the incidence matrices of fixed effects, direct additive genetic effects, maternal genetic effects and permanent environmental effect of the dam; $A$ is the numerator relationship matrix between animals; and oam is the covariance between additive direct and maternal genetic effects. The (co) variance structure for the model was:

$$
\begin{aligned}
& \mathrm{V}(\mathrm{a})=A \sigma_{a}^{2}, \\
& \mathrm{~V}(\mathrm{~m})=A \sigma_{m}^{2}, \\
& \mathrm{~V}(\mathrm{c})=I p \sigma_{c}^{2}, \\
& \mathrm{~V}(\mathrm{e})=I R \sigma_{c}^{2} \\
& \text { And } \operatorname{Cov}(\mathrm{a}, \mathrm{m})=A \sigma_{a m}
\end{aligned}
$$

where $I_{P}$ and $I_{R}$ are identity matrices with orders equal to the number of dams and the number of lambs, respectively and $\sigma_{a}^{2}, \sigma_{m}^{2}, \sigma_{c}^{2}$, and $\sigma_{e}^{2}$ are direct additive genetic variance, maternal additive genetic variance, maternal permanent environmental variance, and residual variance, respectively. Estimates of heritability $\left(\mathrm{h}^{2}\right.$ ), maternal heritability $\left(\mathrm{h}_{\mathrm{m}}^{2}\right)$ and permanent maternal environmental effects $\left(c^{2}\right)$ were calculated as ratios of estimates of $\sigma_{a}^{2}, \sigma_{m}^{2}$, and $\sigma_{c}^{2}$, respectively, to the phenotypic variance $\left(\sigma_{\mathrm{p}}^{2}\right)$. The direct-maternal correlation $\left(\mathrm{r}_{\mathrm{am}}\right)$ was computed as the ratio of the estimates of directmaternal covariance $\left(\sigma_{\mathrm{am}}\right)$ to the product of the square roots of estimates of $\sigma_{a}^{2}$ and $\sigma_{m}^{2}$. The total heritability for each trait was estimated (Willham, 1972) as $\mathrm{h}_{\mathrm{t}}^{2}=$ $\mathrm{h}_{\mathrm{a}}^{2}+0.5 \mathrm{~h}_{\mathrm{m}}^{2}+1.5 \mathrm{mr}_{\mathrm{am}} \mathrm{h}$, which predicts the expected response to phenotypic selection. The total maternal effect, $t_{m}=1 / 4 h_{a}^{2}+h_{m}^{2}+c^{2} m r_{a m} h$ was

calculated to estimate repeatability of ewe performance (Gowane et al., 2010).

\section{RESULTS AND DISCUSSION}

The means, standard deviation (SD) and coefficient of variation (CV \%) of the studied traits are presented in Table (1). The overall means of BW, WW and ADG of Barki lambs were $3.70 \mathrm{~kg}, 20.90$ $\mathrm{kg}$ and $143.09 \mathrm{~g}$, respectively, the corresponding values for Rahmani lambs were $3.52 \mathrm{~kg}, 20.71 \mathrm{~kg}$ and $142.62 \mathrm{~g}$, respectively. Means were higher than those of BW and WW of Barki lambs reported by Gad and El-Wakil (2013), being $3.56 \mathrm{~kg} 19.29 \mathrm{~kg}$ and $131.02 \mathrm{~g}$, respectively and those of Rahmani lambs, being $3.42 \mathrm{~kg}, 19.49 \mathrm{~kg}$ and $135.00 \mathrm{~g}$ as reported by Abbas et al. (2010) on other experimental flocks of sheep in Egypt.

\section{Fixed effects:}


The results of analysis of variance for fixed effects on all studied traits are illustrated in Table 2. Fixed effects on all studied traits were generally significant $(\mathrm{P}<0.01$ or $\mathrm{P}<0.05)$ except for effects of season and year of lambing on BW of Barki lambs and effects of parity on ADG of both breeds. Significant effects of fixed effects on pre-weaning growth traits of lambs of different sheep breeds have been well documented in the literature (Matika et al. 2003, Abegaz et al. 2005, Rashidi et al. 2008,Abbas et al., 2010, Baneh et al., 2010, Jafaroghli et al., 2011; Sofla et al., 2011, Hammoud and Salem, 2012 and Tohidi et al., 2016).

Table 2. Effects of season and year of lambing, sex of lamb, type of lambing and parity on birth weight (BW), weaning weight (WW) and pre-weaning average daily gain (ADG) of Barki and Rahmani lambs

\begin{tabular}{|c|c|c|c|c|c|c|c|c|}
\hline \multirow[t]{2}{*}{ Source of variation } & \multicolumn{4}{|c|}{ Barki } & \multicolumn{4}{|c|}{ Rahmani } \\
\hline & $\mathrm{df}^{*}$ & BW & WW & $\mathrm{ADG}$ & $\mathrm{df}^{*}$ & BW & WW & $\mathrm{ADG}$ \\
\hline Season of lambing & 3 & NS & $* *$ & $* *$ & 3 & $*$ & $* *$ & $* *$ \\
\hline Year of lambing & 6 & NS & $* *$ & $* *$ & 6 & $* *$ & $* *$ & $* *$ \\
\hline Sex of lamb & 1 & $* *$ & $* *$ & $* *$ & 1 & $* *$ & $* *$ & $* *$ \\
\hline Type of lambing & 1 & $* *$ & $* *$ & $* *$ & 1 & $* *$ & $* *$ & $* *$ \\
\hline Parity & 7 & $* *$ & $* *$ & NS & 7 & $* *$ & $*$ & NS \\
\hline Error & & $(575)$ & $(513)$ & (513) & & $(563)$ & $(481)$ & $(481)$ \\
\hline
\end{tabular}

NS: Not significant $(\mathrm{P}>0.05) ; *$ : Significant $(\mathrm{P}<0.05) ; * *$ : Highly significant

Figures within parentheses are the degree of freedom (df) for error. $\mathrm{df}$ of $\mathrm{BW}$ of both

Barki and Rahmani breeds were the same for WW and ADG except for error.

Variance components and heritabilities:

Estimates of variance components $\left(\sigma^{2}, \sigma_{m}^{2}, \sigma_{c}^{2}\right.$, $\sigma_{\mathrm{e}}^{2}$ and $\sigma_{\mathrm{p}}^{2}$ ), heritabilities $\left(\mathrm{h}_{\mathrm{a}}^{2}, \mathrm{~h}_{\mathrm{m}}^{2}\right.$ and $\left.\mathrm{h}_{\mathrm{t}}^{2}\right)$, fraction of variance due to maternal permanent environmental effects $\left(c^{2}\right)$, total maternal effect $\left(t_{m}\right)$ and loglikelihood ( $\log \mathrm{L})$ for BW, WW and ADG of Barki and Rahmani lambs are presented in Table (3).

Model 1, which ignored the permanent environmental and additive maternal effects, had the lowest Log Likelihood values ( $\log$ L) for all studied traits of both Barki and Rahamani lambs. Model 3 that included direct and maternal genetic effects was the most appropriate model for BW, WW and ADG of Barki lamb. Although, the Log L of model 3 and 4 were equal for the two traits, model 3 was considered to be better than model 4 , because the permanent maternal environmental effects in model 4 were equal to zero. Hence the maternal additive effect was determined to be more important than the maternal permanent environmental effect for WW and ADG of Barki lambs. For Rahmani, model 4 that included direct and maternal genetic and permanent maternal environmental effects was the most appropriate model for $\mathrm{BW}$, and model 2 that included direct genetic and permanent maternal environmental effects was the most appropriate model for WW and ADG. However, the log-likelihood of model 2 and 4 were equal for the two traits. Model 2 was considered to be better than model 4 because the maternal effects in model 4 were equal to zero. Hence the permanent environmental effect was determined to be more important than maternal additive effect for WW and ADG of Rahmani lambs.

Model 1, which ignored maternal effects, had the highest estimates of $\sigma^{2}$ and $h^{2}$ for $\mathrm{BW}, \mathrm{WW}$ and ADG of both breeds. The addition of the maternal effects in the models reduced the values of both $\sigma^{2}$ a and $\mathrm{h}^{2}$ a compared to model 1 for all studied traits in both breeds. Duguma et al. (2002) pointed out that if maternal effects constitute a sizable part of genetic variation ignoring these effects results in upward biased estimates of $\mathrm{h} 2 \mathrm{a}$.

The present estimates of $\mathrm{h}_{\mathrm{a}}^{2}$ and $\mathrm{h}_{\mathrm{m}}^{2}$ ranged between $0.161-0.353$ and $0.145-0.147$, from 0.100 0.171 and $0.124-0.124$ and from $0.014-0.172$ and 0.119-0.121 for BW, WW and ADG of Barki lambs, respectively, the corresponding values for Rahmani lambs ranged between 0.204-0.519 and 0.094-0.215, from $0.139-0.168$ and $0-0.021$ and from $0.125-0.144$ and0-0.001, respectively. The relatively low to moderate $\mathrm{h}_{\mathrm{a}}^{2}$ estimates obtained for growth traits in this study except in model 1 for BW of both breeds indicated that direct genetic effects constitute a little portion of the phenotypic variances for the early growth traits of the two breeds. Hence, slow genetic progress would be expected through direct selection for these traits. This can be attributed to the low nutritional level and the differences in managing practices at the sheep breeding station, creating large environmental variations. The estimates of $\mathrm{h}^{2}$ and $\mathrm{h} 2 \mathrm{~min}$ the literature were varied from 0.03 to 0.53 and from 0.02 to 0.45 for $\mathrm{BW}$ and from 0.04 to 0.39 and from 0.01 to 0.038 for WW and from 0.010 to 0.20 and from 0.07 to 0.16 for ADG, respectively depending on the model used and the breed of lamb (Matika et al., 2003, Ekiz et al., 2004, Mandal et al., 2006, Behzadi et al., 2007, Mohammadi and Edriss, 2007, Rashidi et al., 2008, Baneh et al., 2010, Gowane et al., 2010, Mohammedi et al., 2010, Jafaroghli et al., 2011, Mohammedi et al., 2011, Shokrollahi and Baneh, 2012 and Mokhtari et al., 2012). Hence, the present estimates of $h^{2}{ }_{a}$ and $h_{m}^{2}$ for all studied traits are generally in agreement with those reported in the literature on several breeds of sheep.

The model in bold and gray shadow represents the most appropriate model. Values in parentheses are standard error estimates. 
Estimates of $\mathrm{h}^{2}{ }_{\mathrm{a}}$ and $\mathrm{h}^{2}{ }_{\mathrm{m}}$ for body weights showed a tendency to decrease with advance in ages. This tendency has also been reported in several studies (Behzadi et al., 2007 and El-Awady, 2011).The present estimates of $\mathrm{h}^{2}$ and $\mathrm{h}_{\mathrm{m}}^{2}$ for WW and ADG were relatively similar for both breeds. Estimates of h2mfor BW were relatively higher than for WW for Barki lambs and were very lower for Rahmani lambs. Hence, maternal additive effects constitute an important part of variation for BW of both breeds. This probably reflected differences in the uterine capacity for growth of the fetus (Gowane et al., 2010). The estimates of $h_{m}^{2}$ for WW and ADG were larger than $\mathrm{h}_{\mathrm{a}}^{2}$ in Barki lambs, but were very lower in Rahmani lambs. Ozcan et al. (2005) in Turkish Merino sheep reported low estimates of $\mathrm{h}_{\mathrm{m}}{ }_{\mathrm{m}}$ for $\mathrm{WW}$ and ADG of lambs. Several studies showed that including of the maternal effects in the models resulted in more accurate estimation of (co) variance and genetic parameters of growth traits of lambs (Zamani and Mohammadi, 2008; Moktari et al., 2012and Mohammadi et al., 2013).

Estimates of $\mathrm{c}^{2}$ for Barki lambs were relatively important for all studied traits for model 2 only, but were negligible for model 4 . However, estimates of $\mathrm{c}^{2}$ for Rahmani lambs were relatively important for BW in Models 2 and 4, but were different from zero for WW and ADG. Differences in estimates of $\mathrm{c}^{2}$ for BW of lambs were attributed to uterine capacity and the effect of multiple births. Relatively low $\mathrm{c}^{2}$ for WW and ADG are most likely reflected in differences in rearing abilities of ewes that might be influenced by environmental fluctuations between (parities) years of her births (Duguma et al., 2002).

Estimates of the fraction of variance due to maternal permanent environmental effects $\left(\mathrm{c}^{2}\right)$ were ranged from $0.002-0.74,0-0.084$ and $0-0.076$ for BW, WW and ADG of Barki lambs, respectively. The corresponding values for Rahmani lambs ranged between 0.089-0.136, 0.054-0.054 and 0.042-0.042, respectively. These results are in agreement with those reported by Duguma et al. (2002) and Mohammadi and Edriss (2007). They attributed this value to the influence of the uterus and the effect of multiple births. Relatively large $\mathrm{c}^{2}$ estimate for $\mathrm{BW}$ most likely reflected differences in rearing abilities of dams that might be influenced by environmental fluctuations between years or her birth status. The present estimates of $\mathrm{c}^{2}$ for BW, WW and ADG were generally in agreement with those of Abbasi et al. (2012) and Moktari et al. (2012) in Iranian Blauchi and Arman sheep, respectively.

Estimates of the total heritability $\left(\mathrm{h}_{\mathrm{t}}^{2}\right)$ were varied between 0.234-0.353, 0.073-0.171 and 0.072-0.172 for BW, WW and ADG of Bark lambs, respectively, the corresponding values for Rahmani lambs were varied between $0.311-0.519,0.139-0.168$ and 0.125 0.144 , respectively. When maternal effects are important in the expression of a trait $\mathrm{h}_{\mathrm{t}}^{2}$ is of crucial importance in terms breeding and is useful in selection response based on phenotypic values (Abegaz et al., 2005). The $\mathrm{h}_{\mathrm{t}}^{2}$ estimates are model sensitive (Gowane et al., 2010). The obtained estimates of $\mathrm{h}_{\mathrm{t}}^{2}$ for BW were in general in agreement with estimated values reported by Gowane et al. (2010) in Malpura sheep and Moktari et al. (2012) in Arman sheep in Iran.

Estimates of the total maternal effect $\left(\mathrm{t}_{\mathrm{m}}\right)$ were ranged between 0.088-0.187, 0.042-0.127 and 0.0430.123 for $\mathrm{BW}$, WW and $\mathrm{ADG}$ of Barki lambs, respectively. The corresponding values for Rahmani lambs ranged between $0.129-0.252,0.042-0.088$ and $0.036-0.073$, respectively. These results indicated that maternal effects were a significant source of variation for early growth traits of Barki and Rahmani lambs. The present estimates of tm were generally in agreement with those reported by Gowane et al. (2010), Moktari et al. (2012) in Malpura and Arman sheep in Iran.

\section{CONCLUSIONS}

The low to moderate genetic variations in WW and ADG of Barki and Rahmani lambs confirmed that selection for improving any of these traits would result in slow genetic progress. The results showed that including of the maternal effects in the models caused more accurate estimation of variance component and genetic parameters for growth traits of both breeds. Therefore, these effects should be considered when carrying out genetic evaluations of early growth traits of Barki and Rahmani lambs in this flock.

\section{ACKNOWLEDGEMENT}

The authors are grateful to Mr. Ahmed Moustafa Mahmoud, the sheep specialist of the Experimental Station Flock for making the data available.

\section{REFERENCES}

Abbas, S.F., M. Abdl Allah, F.M. Allam and A.A. Abul-Ella, 2010. Growth performance of Rahmani and Chios lambs weaned at different ages. Aust. J. Basic and Appl. Sci., 4: 1583-1589.

Abbasi, M.A., R. Abdollahi-Arpaahli, A. VaezTorshizi and A. Nejati-Javaremi, 2012. Evaluation of models for estimation of genetic parametersand maternal effects for early growth traits of Iranian Baluchisheep.Small Rum. Res., 104: 62-69.

Abegaz, S., J.B. VanWyk and J.J. Oliver, 2005. Model comparisons and genetic and environmental parameter estimates of growth and the Kleiber ratio in Horro sheep. S. Afri. J. Anim. Sci., 35:30-40.

Akhtar, M., K. Javedand M. Abdullah, 2014. Single trait analysis for preweaning growth traits of Buchi sheep in Pakistan. The J. Anim. Plant Sci., 24: 693-699.

Baneh, H., S.H. Hafezian; A. Rashidi;M. GholizadehandG. Rahimi, 2010. Estimation of genetic parameters for body weight traits in 
Ghezel sheep. Asian-Aust.J.Anim.Sci., 23: 149153.

Bayeriyar, M., A.H. Khaltabadi-Farahani and H. Moradi-Shahrbabak, 2011. Estimation of genetic parameter for economic important traits in MoghaniIranian sheep. Afr. J.Biotechnol., 10: 14679-14683.

Behzadi, M.R.B.,F.E.Shahroudi and L.D. Van Vleck, 2007. Estimates of genetic parameters for growth traits in Kermani sheep. J. Anim. Breed. Genet., 124: 296-301.

Duguma, G., L.J. Schoeman, S.W.P. Cloeteanf, G.F. Jordaan, 2002. Genetic parameters of early growth traits in the Tygerhoek Merino Flock. S. Afric. J. Anim. Sci., 32: 66-75.

El-Awady, H.G, 2011. Different Animal Models for estimating genetic parameters of Barki sheep in Egypt. J. American Sci., 7: 882-887.

Ekiz B.,M.Ozcan and A. Yilmaz, 2004. Estimates of genetic parameters for direct and maternal effects with six different models on birth and weaning weight of Turkish Merino lambs. Turk. J. Vet. Anim. Sci., 28: 383-389.

Gad, S.M.A. and S.I. El-Wakil, 2013. Estimates of genetic parameters of early growth traits of Barki sheep in Egypt. J. Animal and Poultry Prod., Mansoura Univ., 4:783-789.

Gowane, G. R., A. Chopra, V. Prakash and A. L. Arora, 2010. Estimates of (co) variance components and genetic parameters for body weights and first greasy fleece weight in Malpura sheep. Livest. Sci., 131: 94-101

Hammoud, M.H. and M.M.I. Salem, 2012. The genetic evaluation of preweaning growth traits of Barki and Rahmani lambs. Alex. J. Agric. Res., 57: 51-57.

Jannoune, A, I. Boujenane, M. Falaki and L. Derqaoui, 2015.Genetic analysis of live weight of Sardi sheep using random regression and multitrait animal models. Small Rumin. Res. 130: 1-7.

Jafari, S., G. Manafiazar; R. Darvishzadeh, S. Razzagzadeh and M. Farhadianl, 2012. Genetic analysisof growth traits in Iranian Makuiesheep breed. Ital. J. Anim Sci., 8:98-102.

Jafaroghli, M., A. Rashidi, M.S. Mokhtar and A.A. Shadparvar, 2010. (Co) variance components and genetic parameter estimates for growth traits in Moghanisheep. Small Rum. Res., 91: 170-177.

Javed, K., A. Iram,M.A. Abdullah,R.Sattar, and M. Akthar, 2013. Genetic trendsfor some productive traits of Lohisheepin Pakistan. Pak. J. Anim. Sci., 65:492-495.

Lalit, Z.S., D.S. Malik, S.P. Dahiya, AnkitMagotra and C.S. Patil, 2015. Genetics of growth traits in sheep: A Review. Int. J. Recent Res. Life Sci., 3: 12-18.

Mandal, A., F.W.C. Neser, P.K. Rout, R. Royand D.R. Notter, 2006. Estimation of direct and maternal (Co) variance components for preweaning growth traits in Muzaffarnagari sheep. Livest. Sci., 99: 79-89.
Matika, O.,J.B.VanWyk, G.J. ErasmusandR.L. Baker, 2003. Genetic parameter estimates in Sabi sheep. livest. Prod. Sci., 79: 17-28.

Meyer, K. (2006). WOMBAT - Digging deep for quantitative genetic analyses by restricted maximum likelihood. Proc. 8th World Congress of Genetics Applied for Livestock Production, Communication No. 27-14.17.

Mohammadi, H. and M.A. Edriss, 2007. Genetic parameters of earl growth traits in Mehraban breed of sheep. Pak. J. Biol. Sci., 10: 373-377.

Mohammadi, H., M. Moradi-Shahrebabak, H. Moradi-Shahrebabak, A. Bahrami, and M. Dorostkar, 2013. Model comparisons and genetic parameter estimates of growth and the Kleiber ratio in Shal sheep. Archiv Tierzucht, 56, 264275.

Mohammadi, Y., A. Rasihdi, M. S. MokhariI and A. K. Esmilizadeh, 2010. Quantitative genetic analysis of growth traits and Kleiber ratios in Sanjabi sheep. Small Rum. Res., 93: 88-93.

Mohammadi, K., A. Rasihdi, M. S. MokhariI and A. K. Esmilizadeh, 2011.The estimation of (co)variance components for growth traits for growth traits and Kleiber ratios in Zandai sheep. Small Rum. Res., 99: 116-121.

Mokhtari, M.S., M. Moradi-Sharebabak., H. MoradiSharebabak, and M. Sadeghi, 2012.Estimation of (co) variance components and genetic parameters for growth traits in Arman sheep. J. Livest .Sci. and Techno., 1: 38-47.

Ozcan, M., B. Ekiz, A. Yilmaz and A. Ceyhan, 2005. Genetic parameters estimates of lamb growth traits and greasy fleece weight at first shearing in Turkish Merino sheep. Small Rumin. Res., 56:215-222.

Rashidi, A.,M.S. Mokhtar, A. S. Jahanshahi and M.R. Mohammad-Abadi, 2008. Genetic parameters estimates of preweaning growth traits in Kermani sheep. Small Rum. Res., 74:165-171.

Roshanfekr, H., P. Berg, K. Mohammadi and E. M. Mohamadi, 2015. Genetic parameters and genetic gains for reproductive traits of Arabi sheep. Biotechnol. Anim. Husb., 31: 23-36, 2015.

SAS, 2008. Statistics Analysis System user's Guide, (Release 9.2). SAS Institute Inc., Cary, North Carolina, USA.

Shokrollahi, B. and H. Baneh, 2012. (Co) variance components and genetic parameters for growth traits in Arabi sheep using different animal model. Genet. and Mole. Res., 11: 305-314.

Sofla, S.S., A.N. Javarmiand M.A. Abbasi, 2011. Investigation on direct and maternal effects on growth traits and the Kleiber Ratio in Moghani sheep. World Applied Sci. J., 14: 1313-1319.

Tosh, J.J. and R. A. Kemp, 2011. Estimation of variance components for lamb weights in three sheep populations. J. Anim. Sci., 72: 1184-1190.

Tohidi, R., A. Javanm and V. Shamsabadi, 2016. Analysis of the non-genetic factors affecting the 
growth traits of Balouchi sheep. J.Bio.Env. Sci., 8: 67-73.

Willham, R.L, 1972. The role of maternal effects in Animal breeding; III. Biometrical aspects of maternal effects in animal. J. Anim. Sci., 35, $1288-1293$.

Yilmaz, O.,H. Denkand D. Bayram, 2007. Effects of lambing season, sex and birth type on growth performance in Norduz lambs. Small Rumin. Res., 68: 336-339

Zamani, P. and H. Mohammadi, 2008. Comparison of different models for estimation of genetic parameters of early growth traits in the Mehraban sheep. J. Anim. Breed. Genet., 125: 29-34.

تقديرات مكونات التباين والمكافيء الوراثي لصفات النمو قبل الفطام للحملان البرقى والرحمانى

محمد حسن حمود ، محمد محمود سالم

قسم الإنتاج الحيوانى، كلية الزراعة، جامعة الإسكندرية

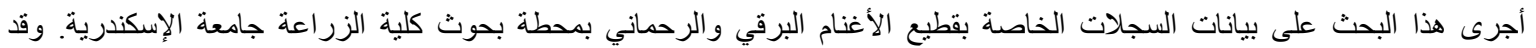

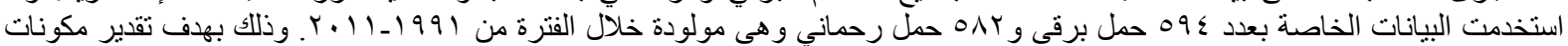

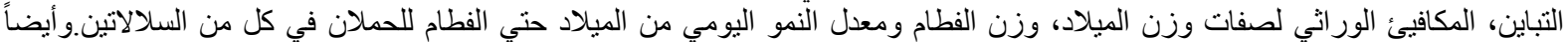

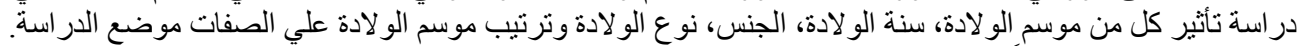

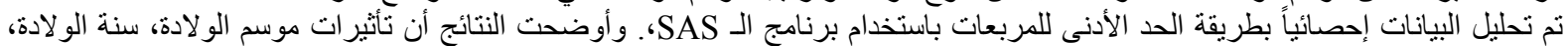

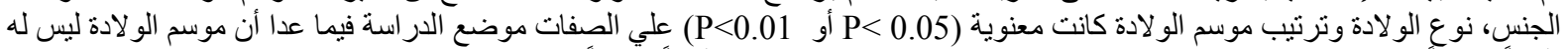

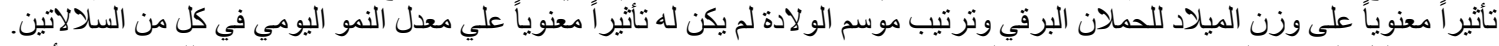

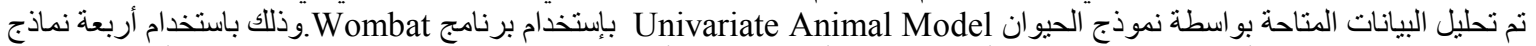

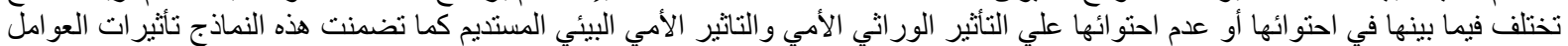

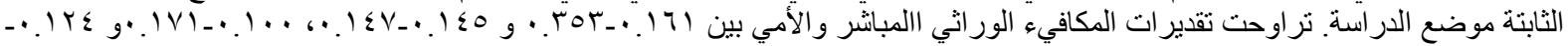

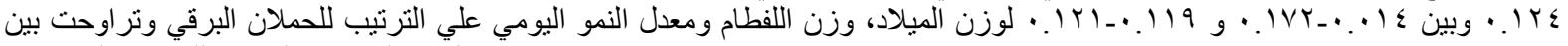

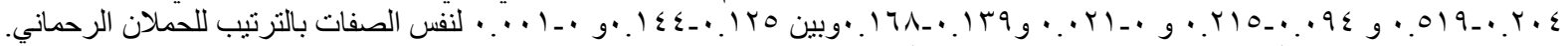

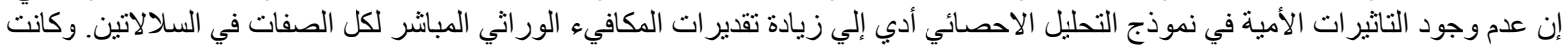

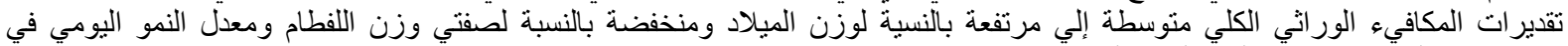

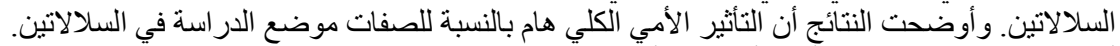

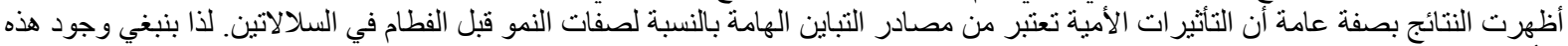

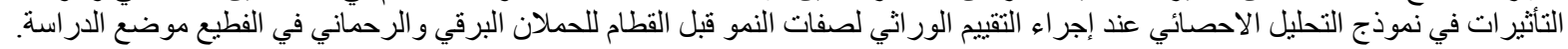


Table 3 Estimates of (co)variance components and genetic parameters for birth weight (BW), weaning weights (WW), and average daily gain (ADG) of Barki (B) and Rahmani (R) lambs

\begin{tabular}{|c|c|c|c|c|c|c|c|c|c|c|c|c|c|}
\hline Breed & Trait & Model & $\sigma_{a}^{2}$ & $\sigma_{m}^{2}$ & $\overline{\sigma_{c}^{2}}$ & $\sigma_{\mathrm{e}}^{2}$ & $\sigma_{p}^{2}$ & $\mathrm{~h}_{\mathrm{a}}^{2}$ & $\mathrm{~h}_{\mathrm{m}}^{2}$ & $\mathrm{c}^{2}$ & $\mathrm{~h}_{\mathrm{t}}^{2}$ & $\mathrm{t}_{\mathrm{m}}$ & Log-1 \\
\hline \multirow{10}{*}{ B } & \multirow{5}{*}{ BW } & M1 & 0.149 & - & - & 0.274 & 0.424 & $0.353(0.099)$ & - & - & 0.353 & 0.088 & -51.20 \\
\hline & & M2 & 0.120 & - & 0.031 & 0.268 & 0.420 & $0.282(0.110)$ & - & $0.074(0.046)$ & 0.282 & 0.144 & -49.70 \\
\hline & & M3 & 0.070 & 0.061 & - & 0.287 & 0.415 & $0.161(0.112)$ & $0.147(0.063)$ & - & 0.234 & 0.187 & -47.90 \\
\hline & & M4 & 0.070 & 0.060 & 0.001 & 0.287 & 0.415 & $0.162(0.114)$ & $0.145(0.089)$ & $0.002(0.059)$ & 0.234 & 0.187 & -47.94 \\
\hline & & M1 & 9.519 & - & - & 46.181 & 55.701 & $0.171(0.091)$ & - & - & 0.171 & 0.042 & -1452.2 \\
\hline & \multirow{5}{*}{ WW } & M2 & 5.254 & - & 4.624 & 44.982 & 54.861 & $0.100(0.084)$ & - & $0.084(0.046)$ & 0.100 & 0.109 & -1450.2 \\
\hline & & M3 & 0.630 & 6.790 & - & 47.277 & 54.690 & $0.012(0.060)$ & $0.124(0.051)$ & - & 0.074 & 0.127 & -1448.1 \\
\hline & & M4 & 0.617 & 6.800 & 0.001 & 47.283 & 54.700 & $0.011(0.060)$ & $0.124(0.073)$ & $0.0(0.060)$ & 0.073 & 0.126 & -1448.1 \\
\hline & & M1 & 491.98 & - & - & 2371.0 & 2863.0 & $0.172(0.091)$ & - & - & 0.172 & 0.043 & -2566.9 \\
\hline & & M2 & 288.170 & - & 215.330 & 2317.8 & 2821.3 & $0.102(0.085)$ & - & $0.076(0.045)$ & 0.102 & 0.102 & -2565.28 \\
\hline \multirow{14}{*}{$\mathrm{R}$} & \multirow[t]{4}{*}{$\mathrm{ADC}$} & M3 & 38.925 & 334.800 & - & 2432.4 & 2806.2 & $0.014(0.062)$ & $0.119(0.050)$ & - & 0.072 & 0.123 & -2562.9 \\
\hline & & M4 & 38.419 & 340.860 & 0.083 & 2433.6 & 2813.0 & $0.014(0.062)$ & $0.121(0.072)$ & $0.0(0.059)$ & 0.075 & 0.123 & -2562.9 \\
\hline & & M1 & 0.203 & - & - & 0.219 & 0.422 & $0.519(0.097)$ & - & - & 0.519 & 0.129 & -33.16 \\
\hline & & M2 & 0.156 & - & 0.056 & 0.201 & 0.414 & $0.878(0.121)$ & - & $0.136(0.049)$ & 0.378 & 0.230 & -26.98 \\
\hline & \multirow[t]{3}{*}{ BW } & M3 & 0.084 & 0.088 & - & 0.240 & 0.413 & $0.204(0.125)$ & $0.215(0.068)$ & - & 0.311 & 0.266 & -27.45 \\
\hline & & M4 & 0.112 & 0.040 & 0.040 & 0.221 & 0.408 & $0.276(0.140)$ & $0.094(0.091)$ & $0.089(0.091)$ & 0.323 & 0.252 & -26.36 \\
\hline & & M1 & 10.396 & - & - & 51.420 & 61.780 & $0.168(0.091)$ & - & - & 0.168 & 0.042 & -1456.87 \\
\hline & \multirow{4}{*}{ WW } & M2 & 8.557 & - & 3.301 & 49.740 & 61.600 & $0.139(0.090)$ & - & $0.054(0.045)$ & 0.139 & 0.088 & -1456.1 \\
\hline & & M3 & 9.205 & 1.308 & - & 51.27 & 61.785 & $0.149(0.101)$ & $0.021(0.047)$ & - & 0.159 & 0.058 & -1456.8 \\
\hline & & M4 & 8.561 & 0.100 & 3.305 & 49.73 & 61.600 & $0.139(0.097)$ & $0(0.050)$ & $0.054(0.055)$ & 0.139 & 0.088 & -1456.1 \\
\hline & & M1 & 445.01 & - & - & 2655.7 & 3100.7 & $0.144(0.086)$ & - & - & 0.144 & 0.036 & -2547.68 \\
\hline & \multirow[t]{3}{*}{$\mathrm{AD}$} & M2 & 388.190 & - & 129.170 & 2579.6 & 3096.9 & $0.125(0.086)$ & - & $0.042(0.043)$ & 0.125 & 0.073 & -2547.18 \\
\hline & & M3 & 444.980 & 1.654 & - & 2654.4 & 3101.3 & $0.143(0.098)$ & $0.001(0.041)$ & - & 0.144 & 0.036 & -2547.68 \\
\hline & & M4 & 38.300 & 0.006 & 129.024 & 2579.5 & 3097.0 & $0.125(0.092)$ & $0(0.053)$ & $0.42(0.052)$ & 0.125 & 0.073 & -2547.18 \\
\hline
\end{tabular}

$\sigma_{\mathrm{a}}^{2}$ : direct additive genetic variance, $\sigma_{\mathrm{m}}^{2}$ : maternal genetic variance, $\sigma_{\mathrm{e}}^{2}$ : residual (temporary environmental variance), $\sigma_{\mathrm{p}}^{2}:$ phenotypic variance, $\mathrm{h}_{\mathrm{a}}^{2}:$ direct heritability and $\mathrm{h}_{\mathrm{m}}^{2}$ : maternal heritability, $\mathrm{c}^{2}$ : fraction of phenotypic variance due to maternal permanent environmental effects. $\mathrm{h}_{\mathrm{t}}^{2}$ : total heritability $\left(\mathrm{h}_{\mathrm{t}}^{2}=\mathrm{h}_{\mathrm{a}}^{2}+0.5 \mathrm{~h}_{\mathrm{m}}^{2}+1.5 \mathrm{mr}_{\mathrm{am}} \mathrm{h}\right), \mathrm{t}_{\mathrm{m}}$ : total maternal effect $\left(\mathrm{t}_{\mathrm{m}}=1 / 4 \mathrm{~h}_{\mathrm{a}}^{2}+\mathrm{h}_{\mathrm{m}}^{2}+\mathrm{c}^{2}+\mathrm{mr}_{\mathrm{am}} \mathrm{h}\right)$, and log-l: log- likelihood value 